\title{
Paediatric Redo Urethroplasty for Hypospadias: A Comparative Evaluation
}

\author{
Shah Md. Ahsan Shahid ${ }^{1, ~ *, ~ M d . ~ N a w s h a d ~ A l i ~}{ }^{1}$, Khondokar Seheli Nasrin Lina ${ }^{2}$, \\ Md. Kamruzzaman ${ }^{3}$, Md. Humayun Reza ${ }^{4}$ \\ ${ }^{1}$ Department of Pediatric Surgery, Rajshahi Medical College, Rajshahi, Bangladesh \\ ${ }^{2}$ Department of Gynaecology and Obstetrics, Rajshahi Medical College, Rajshahi, Bangladesh \\ ${ }^{3}$ Department of Surgery, 250 Bed District Sadar Hospital, Feni, Bangladesh \\ ${ }^{4}$ Department of Orthopaedic Surgery, Shaheed M. Monsur Ali Medical College, Sirajganj, Bangladesh
}

Email address:

smashahid293@gmail.com (S. Md. A. Shahid)

*Corresponding author

\section{To cite this article:}

Shah Md. Ahsan Shahid, Md. Nawshad Ali, Khondokar Seheli Nasrin Lina, Md. Kamruzzaman, Md. Humayun Reza. Paediatric Redo Urethroplasty for Hypospadias: A Comparative Evaluation. Advances in Surgical Sciences. Vol. 8, No. 2, 2020, pp. $27-33$. doi: $10.11648 /$ j.ass.20200802.13

Received: February 5, 2020; Accepted: April 9, 2020; Published: September 7, 2020

\begin{abstract}
Introduction: The burden of a failed hypospadias repair can be devastating for a patient and his family. Urethrocutaneous fistula after hypospadias surgery is the most common complication and remains a frustrating problem that precludes the goal of hypospadias surgery leading to failure of primary surgery. Aim of the Study: The aim of this study was to assess the outcome of pediatric salvage urethroplasty for hypospadias and to compare among three procedures. Material \& Methods: It was an interventional study which was carried out from July 2011 to June, 2016 in the Department of Paediatric Surgery, Rajshahi Medical College Hospital, Rajshahi, Bangladesh. The study was designed with randomized control trial. Simple Random sampling technique was followed to select groups for each sample by means of lottery. BM GRAFT (Buccal Mucosal Graft) was grouped as group A, DORSAL FLAP (Dorsal transposition flap) was grouped as group B, FLIP FLAP (Distally based flip-flap) was grouped as group C. The primary outcome measure was the evaluation of the recurrence of fistula among the surgical procedures. For a valid comparison of the outcomes of traditional and innovative surgical procedures patients were evaluated by objective scoring system. Informed consent was obtained from parents in the consent form. Collected data was arranged in systemic manner, presented in various tables and figures and statistical analysis was made to evaluate the objectives of this study with the help of SPSS. Results: The age range of the studied patients were started from 2 to 13 years and was divided into three age groups such as 2-5 years, 6-9 years and 10-13 years. Out of total 189 patient's BM graft consisted 61 patients, Dorsal flap comprised 69 patients and Flip flap patient consisted 59 patients. The distribution patterns of prior types of surgeries were presented, which showed that among the preceding primary procedures Tubularized incised plate urethroplasty (TIP) demonstrated highest frequency. The differences of re-fistula rate in primary surgery were significantly less in Buccal Mucosal Graft group (group A) in comparison to Distally based flip-flap group (group C) and Dorsal transposition flap group (group B), at $\mathrm{p}<0.05$. It was observed that the fistula recurrence frequency of secondary surgery was higher than primary surgery among the three tested redo urethroplasty groups. Duncan multiple range test (DMRT) revealed that refistula was higher at the sub- coronal area than other locations in case of flip-flap (46.66\%) and BM groups (42.85\%). Conclusion: Staged repair using buccal mucosa was a better option for urethral reconstruction in large ( $>4 \mathrm{~mm})$ or multiple -small $(<4 \mathrm{~mm})$ fistulae, than dorsal transposition flap and flip flap procedures (group A> group B $>$ group C).
\end{abstract}

Keywords: Hypospadias Surgery, Urethrocutaneous Fistula, Surgical Procedure, Buccal Mucosal Graft, Dorsal Transposition Flap, Distally Based Flip-Flap 


\section{Introduction}

Hypospadias surgery is still endowed with a complication rate that even in this era is quite high. Urethrocutaneous fistula is the most common complication of hypospadias surgery. Fistula rate after a particular procedure is often cited as a measure of effectiveness of that surgical procedure. The complexity of these cases was highlighted by the largest report to date on failed hypospadias by Barbagli et al. [1] In that retrospective descriptive analysis, 1,176 patients with failed hypospadias, a median of five additional procedures (ranging from 2-23) were required to achieve a satisfactory final result. The modern era of hypospadias surgery has seen major technical advances. This repair not only involves urethroplasty, but also has its goal in achieving good cosmetic results with a straight normal proportioned penis and an orthotopic meatus, in addition to the functional urethra of adequate caliber. However, description of over 250 procedures for hypospadias repair suggests lack of uniformity of results and high-complication rates. There still is room and therefore need for further improvement in this field. [2, 3] Each repair attempt, further depletes local resources for any repair, that would be required later. So, the management of these complications in patients, in whom multiple attempts of hypospadias repair had failed, is a surgical challenge and still represents a complex problem for reconstructive urologists. Often this difficult population of patients has been left with deformities significantly worse than the primary congenital anomaly. [4, 5] Reoperative urethroplasty after failed hypospadias surgery is usually done with principles used for primary repairs. But renewed controversy exists over the best means of reconstructing the penile urethra in this difficult population of patients. [6, 7] The majority of publications in hypospadias literature present single-center and single-surgeon retrospective case series. High-quality randomized trials in paediatric urology are extremely challenging and therefore rarely performed. [8] This fact remains true in the literature of failed hypospadias in Bangladesh, where no randomized comparative study yet has been carried out on the procedures of failed hypospadias due to urethrocutaneous fistula. So, the better surgical method for treatment of urethrocutaneous fistula after previous failed hypospadias reconstruction is still unknown. Keeping the above points in mind, the present research work was undertaken and comparison was made among procedures using substitution of skin flaps or buccal mucosal graft in a controlled situation, with the objective to find a better method for salvage urethroplasty.

\section{Methodology and Materials}

It was an interventional study which was carried out from July 2011 to June, 2016 in the Department of Paediatric Surgery, Rajshahi Medical College Hospital, Rajshahi, Bangladesh. The study was designed with randomized control trial. Simple Random sampling technique was followed to select groups for each sample by means of lottery. BM GRAFT (Buccal Mucosal Graft) was grouped as group A, DORSAL FLAP (Dorsal transposition flap) was grouped as group B, FLIP FLAP (Distally based flip-flap) was grouped as group C. Each patient in every groups received a same standard schedule of management regarding preoperative assessment, Control of infection and analgesia and assessment of outcome. Patients were followed in outpatient clinic at scheduled interval up to one year. Recurrence of fistula, residual chordee, meatal stenosis, take of the graft /flap were observed. At the follow up visits the urinary stream was assessed by observing the patient during voiding. Presence or absence of terminal voiding and nature of urinary stream was noted. The site and the shape of the meatus determined, and the new urethra calibre measured by a well lubricated plastic catheter. urethral dilatation regimen was assessed. Cosmetic outcome was assessed. The incidence and type of complications as fistulae, stenosis or recurrence were recorded and managed. The primary outcome measure was the the recurrence of fistula among the surgical procedures. For a valid comparison of the outcomes of traditional and innovative surgical procedures patients were evaluated by objective scoring system. Informed consent was obtained from parents in the consent form. In each case, detail information about the patient was collected from the parents or accompanying guardians or from the patients in older age group. Collected data was arranged in systemic manner, presented in various tables and figures and statistical analysis was made to evaluate the objectives of this study with the help of SPSS.

Inclusion criteria: Paediatric patients with previous failed hypospadias repair presented with a persistent fistula and supple dorsal skin were included in the study. A minimum of 1 year was allowed to elapse following the last failed repair.

Exclusion criteria: Patients with single pinhole or small (< $4 \mathrm{~mm})$ fistula and Multiple -large $(>4 \mathrm{~mm})$ fistula; Patients with urethral diverticulum and urethral stricture; Patients with severe other surgical, medical problems; Fistula over coronal, penoscrotal, scrotal or perineal location; Patient with glans deformity and total disruption; Patients with persistent severe chordee were excluded.

\section{Results}

The age-wise distribution of failed hypospadias patients of the current study was depicted [Table 1]. As shown in the table, age ranged from 2 to 13 years and was divided into three age groups such as 2-5 years, 6-9 years and 10-13 years. Out of total 189 patient's BM graft consisted 61 patients, Dorsal flap comprised 69 patients and Flip flap patient consisted 59 patients. Among them, 6-9-year age group consisted highest number of patients (77) out of the total figure (189) and in BM graft (27) and Flip- flap groups (29). But 10-13-year age group consisted the highest number of patients (32) in Dorsal transposition flap group.

The distribution patterns of prior types of surgeries were presented [Table 2]. Among the preceding primary procedures Tubularized incised plate urethroplasty (TIP) 
demonstrated highest frequency with a Mean \pm SE (22.00土1.73). The number of patients distributed for TIP among the three procedures were as follows; in Dorsal flap group (25), Flip flap (19) and BM graft (22). Mean \pm SE values for other primary procedures were as follows: Mathieu (12.33 \pm 1.20$)$, Lateral based flap (8.33 \pm 1.45$)$, staged procedure $(9.67 \pm 1.45)$ respectively and for Secondary surgery was $(10.67 \pm 0.88)$. The number of patients distributed for Secondary surgery among the three procedures were as follows; in Dorsal flap group (12), Flip flap (9) and BM graft (11) [Table 3] demonstrated the comparison early postoperative complications among the three groups under study. Haematoma showed the highest frequency in dorsal flap group $(24.63 \%)$; followed by Flip flap $(11.86 \%)$ and BM graft $(11.47 \%)$. Percentage distribution of Haemorrhage was as follows: in Dorsal flap group (17.39\%); Flip flap (15.25\%) and BM graft $(6.55 \%)$. [Table 4] demonstrated the comparison early post-operative complications- urine retention and wound infection among the three groups under study. Urine retention showed the highest frequency in Flip flap group (18.64\%); followed by Dorsal flap (15.94\%) and BM graft $(6.55 \%)$. Percentage distribution of wound infection was as follows: in Dorsal flap group (28.98\%); Flip flap $(22.03 \%)$ and BM graft $(13.11 \%)$. The differences of values of early post-operative complications were insignificant among the three groups under study. [Table 5] demonstrated the comparison early post-operative complications- increased salivation and perioral numbness among the three groups under study. Increased salivation showed the highest frequency BM graft (31.14\%). in Flip flap group and Dorsal flap groups frequencies were $(0.00 \%)$ as these groups did not had any donor site. and Percentage distribution of perioral numbness was as follows: in Dorsal flap group (0.00\%) Flip flap (0.00\%) and BM graft $(22.95 \%)$ due to similar reasons. The differences of values of early post-operative complications were significantly higher at $\mathrm{p}$ $<0.01$, in BM group. The fistula recurrence frequencies of primary surgery were almost equal in dorsal flap (26.32\%) and Flip flap (26.00\%) groups and the lowest frequency was recorded in BM graft (16.00\%) procedure [Table 6]. It was observed that the fistula recurrence frequency of primary surgery was lower than secondary surgery among the three tested salvage urethroplasty groups. The differences of refistula rate in primary surgery were significantly less in Buccal Mucosal Graft group (group A) in comparison to Distally based flip-flap group (group C) and Dorsal transposition flap group (group B), at $p<0.05$. Fistula recurrence in relation to previous secondary surgery was depicted [Table 7]. It was observed that the fistula recurrence frequency of secondary surgery was higher than primary surgery among the three tested salvage urethroplasty groups. Fistula recurrence rate of secondary surgery was noted $66.67 \% ; 50.00 \%$ and $27.27 \%$ in Flip flap, dorsal flap and BM graft respectively. Fistula recurrence in relation to preoperative position was presented [Table 8]. Different types of urethrocutaneous fistula included in present study were Sub coronal, Distal penile, mid penile and Proximal penile. Other varieties of urethrocutaneous fistula were excluded from the study. In this study distribution of patients with recurrent urethrocutaneous fistula in sub coronal position among three procedures were as follows: BM graft (6), Dorsal flap (3), Flip flap (7). Distribution of patients with recurrent urethrocutaneous fistula in Distal penile position among three procedures were as follows: graft (2), Dorsal flap (4), Flip flap (5). Again, distribution of patients with recurrent urethrocutaneous fistula in Mid penile position among three procedures were as follows: BM graft (1), Dorsal flap (6), Flip flap (4). On the other hand, distributions of patients in proximal penile type among three procedures were, BM graft (2), dorsal flap (8), Flip flap (3). Duncan multiple range test (DMRT) revealed that refistula was higher at the sub- coronal area than other locations in case of flipflap (46.66\%) and BM groups (42.85\%). Refistula rate was higher in proximal penile $((53.33 \%)$ locations in Dorsal transposition Flaps. Within group analysis showed that the differences were significant, at $\mathrm{P}<0.05$, according to DMRT. Comparison of functional outcome [Table 9].

Table 1. Age distribution of failed hypospadias patients. $(n=189)$.

\begin{tabular}{llllll}
\hline \multirow{2}{*}{ Age (years) } & \multirow{2}{*}{ Age (years) } & Methods & & & Flip flap \\
\cline { 3 - 6 } & & BM graft & Dorsal flap & 13 & Total \\
\hline $2-5$ & $2-5$ & 19 & 16 & 29 & 48 \\
$6-9$ & $6-9$ & 27 & 21 & 17 & 77 \\
$10-13$ & $10-13$ & 15 & 32 & 59 & 64 \\
Total & & 61 & 69 & 189 \\
\hline
\end{tabular}

Table 2. Distribution of the patients by Pattern of previous surgery.

\begin{tabular}{llllll}
\hline Prior operation & Technique & BM graft $(\boldsymbol{n}=\mathbf{6 1})$ & Dorsal flap $(\boldsymbol{n}=\mathbf{6 9})$ & Flip flap $(\boldsymbol{n}=\mathbf{5 9})$ & Mean \pm SE \\
\hline \multirow{3}{*}{ Primary } & Mathieu & 10 & 14 & 13 & $12.33 \pm 1.20$ \\
surgery & TIP & 22 & 25 & 19 & $22.00 \pm 1.73$ \\
& Two stage & 10 & 7 & 12 & $9.67 \pm 1.45$ \\
Secondary surgery & Lateral based flap & 8 & 11 & 6 & $8.33 \pm 1.45$ \\
\hline
\end{tabular}


Table 3. Post-operative complications for Haematoma and Haemorrhage.

\begin{tabular}{|c|c|c|c|c|c|c|}
\hline \multirow{3}{*}{ Early Complications } & \multicolumn{6}{|c|}{ Methods } \\
\hline & \multicolumn{2}{|c|}{ BM graft } & \multicolumn{2}{|c|}{ Dorsal flap } & \multicolumn{2}{|c|}{ Flip flap } \\
\hline & $N(61)$ & $\%$ & $N(69)$ & $\%$ & $N(59)$ & $\%$ \\
\hline Haematoma & 7 & 11.47 & 17 & 24.63 & 7 & 11.86 \\
\hline Haemorrhage & 4 & 6.55 & 12 & 17.39 & 9 & 15.25 \\
\hline
\end{tabular}

NS= Not significant; $P$ value reached from Chi Square test.

Table 4. Post-operative complications for Urine retention and Infection.

\begin{tabular}{|c|c|c|c|c|c|c|}
\hline \multirow{3}{*}{ Complications } & \multicolumn{6}{|c|}{ Methods } \\
\hline & \multicolumn{2}{|c|}{ BM graft } & \multicolumn{2}{|c|}{ Dorsal flap } & \multicolumn{2}{|c|}{ Flip flap } \\
\hline & $N(61)$ & $\%$ & $N(69)$ & $\%$ & $N(59)$ & $\%$ \\
\hline Urine retention & 4 & 6.55 & 11 & 15.94 & 11 & 18.64 \\
\hline Infection & 8 & 13.11 & 20 & 28.98 & 13 & 22.03 \\
\hline
\end{tabular}

$\mathrm{NS}=$ Not significant; $\mathrm{P}$ value reached from Chi Square test.

Table 5. Post-operative complications for increased salivation and Perioral numbness.

\begin{tabular}{|c|c|c|c|c|c|c|}
\hline \multirow{3}{*}{ Early Complications } & \multicolumn{6}{|c|}{ Methods } \\
\hline & \multicolumn{2}{|c|}{ BM graft } & \multicolumn{2}{|c|}{ Dorsal flap } & \multicolumn{2}{|c|}{ Flip flap } \\
\hline & $n$ & $\%$ & $n$ & $\%$ & $n$ & $\%$ \\
\hline Increased salivation & 19 & $31.14^{*}$ & 0 & 0.00 & 0 & 00 \\
\hline Perioral numbness & 14 & $22.95 *$ & 0 & 0.00 & 0 & 0.00 \\
\hline
\end{tabular}

* significantly different from dorsal transposition flap (group B) and distally based flip-flap (group C), p <0.01.

$P$ value reached from Chi Square test.

Table 6. Fistula recurrence in three groups in relation to previous primary surgery.

\begin{tabular}{|c|c|c|c|}
\hline \multirow{2}{*}{ Prior operation } & \multicolumn{3}{|l|}{ Methods } \\
\hline & BM graft & Dorsal flap & Flip flap \\
\hline Primary surgery & $8(16.00 \%) * n=50$ & $15(26.32 \%) n=57$ & $13(26.00 \%) n=50$ \\
\hline
\end{tabular}

* Significantly different from dorsal transposition flap (group B) and distally based flip-flap (group C), at $\mathrm{p}<0.05$.

$\mathrm{P}$ value reached from $\mathrm{t}$ test.

Table 7. Fistula recurrence in relation to previous secondary surgery.

\begin{tabular}{llll}
\hline \multirow{2}{*}{ Prior operation } & Methods & & \\
\cline { 2 - 5 } & BM graft & Dorsal flap & Flip flap \\
\hline Secondary surgery & $3(27.27 \%) *_{n=11}$ & $6(50.00 \%) *_{n=12}$ & $6(66.67 \%) *_{n=9}$ \\
\hline
\end{tabular}

* Significantly different from dorsal transposition flap (group B) and distally based flip-flap (group C), at p <0.05.

$\mathrm{P}$ value reached from $\mathrm{t}$ test.

Table 8. Distribution of fistula recurrence in relation to preoperative position.

\begin{tabular}{|c|c|c|c|}
\hline Type of fistula & BM graft & Dorsal flap & Flip flap \\
\hline Sub Coronal & $6(42.85 \%)(n=14)$ & $3(18.75 \%)(n=16)$ & $7(46.66 \%)(n=15)$ \\
\hline Distal & $2(10.52 \%)(n=19)$ & $4(22.22 \%)(n=18)$ & $5(26.31 \%)(n=19)$ \\
\hline Midpenile & $1(6.66 \%)(n=15)$ & $6(30 \%)(n=20)$ & $4(28.57 \%)(n=14)$ \\
\hline Proximal penile & $2(15.38 \%)(n=13)$ & $8(53.33 \%)(n=15)$ & $3(27.27 \%)(n=11)$ \\
\hline
\end{tabular}

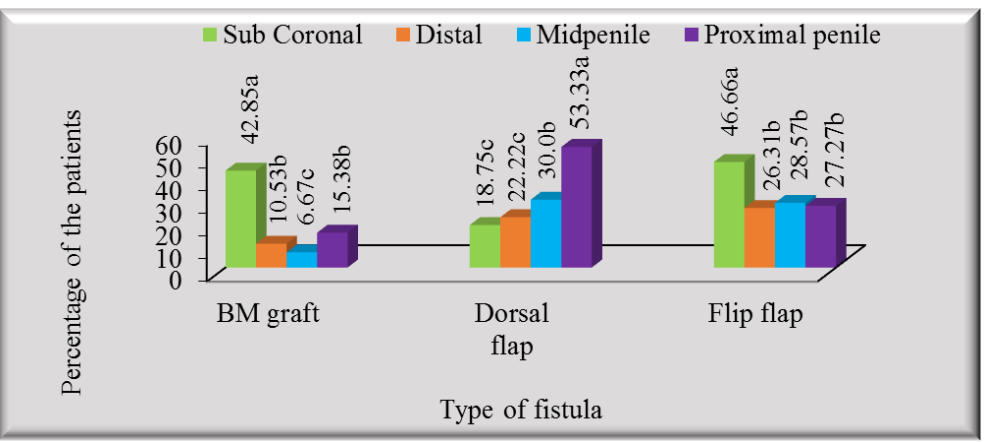

Figure 1. Figure of analysis fistula recurrence by Duncan multiple range test (DMRT). 
Table 9. Comparison of Functional outcome.

\begin{tabular}{lll}
\hline \multirow{2}{*}{ Functional outcome parameters } & Methods & \\
\cline { 2 - 3 } & BM graft N (61) & Dorsal Flap N (69) \\
\hline Patients with obstructive voiding symptoms & $11(18.03 \%)$ & $17(24.63 \%)$ \\
Significant post voidal residue & $3(4.91 \%)$ & $6(8.69 \%)$ \\
\hline
\end{tabular}

$\mathrm{NS}=$ Not significant, $\mathrm{P}$ value reached from Chi Square test

\section{Discussion}

This study is a randomized controlled trial, in a single institute over five years period (from July 2011 to June, 2016). During this period, 372 failed hypospadias cases due to urethrocutaneous fistula were operated. Out of which, 189 patients were included in present study as per inclusion and exclusion criteria and randomized in the three groups under study. Comparison was made among three procedures of salvage urethroplasty for failed hypospadias due to urethrocutaneous fistula, using substitution of dorsal transposition flap, Flip-flap, or buccal mucosal graft in a controlled situation, with the objective to find a better method for salvage urethroplasty. Outcome was assessed by means of overall success rates, major complication rates, cosmetic appearance, functional results, patient's compliance and by objective scoring system. In the present study majority of patients had undergone a variety of hypospadias repairs in the past. The former types of primary or secondary surgeries were obtained from history and clinical records. Among the previous primary urethroplasty types "Tubularized Incised Plate" (TIP) was the commonest procedure (Mean \pm SE; 22.00 \pm 1.73 ). These findings were equivalent to our previous reports, $[9,10]$ where TIP procedure was considered to be as a versatile method for primary hypospadias repair. However, the number and types of previous procedures did not negatively influence the comparative analysis, as the differences in percentage distribution of the cases in three groups were insignificant. Similar observations were described by Yassin et al. [11] No significant difference was observed by them, when comparing some variables, for example, patient age, associated anomalies and types of original hypospadias. It was difficult to conduct a randomized trial on urethroplasty techniques because many variables could influence the surgical management and outcome. As described by Dubey et al. [12] the factors that might affect results of redo urethroplasty, could be the conditions of local tissue, duration of time after hypospadias repair, the number, location and size of the fistula, use of magnification and also the type of suture material used, skill of the operating surgeon and proper inversion of the edges etc. In the present study, all those variables that might affect outcome were kept minimum. Uniformity for randomization in three groups was maintained by excluding wide range of variables by exclusion criteria, mentioned in methodology. Redo surgeries were postponed for at least one year to get excellent results and to enable the scars to mature and also the oedema and induration to subside. This view was suggested by Retik et al. [13] Similar protocol was followed in all three groups for the same reasons.

In this study age group of the patients ranged from two to thirteen years. Among them, six to nine year age group, consisted highest number of patients (77). Though there is difference of opinion regarding ideal age for hypospadias surgery, American Academy of Pediatrics [14] noted that mainly for psychological reasons, hypospadias repair was generally performed when patients are aged about 12 months. $[14,15]$ Early surgery generally means that the patient is more likely to accept his own body image, thereby improving patient satisfaction. [16] Some evidence suggests that performing surgery at a younger age also decreases the risk of complications [17] However, hypospadias repair may also fail many years after achieving successful functional and cosmetic results by primary repair and a urethral stricture may develop decades after the initial hypospadias surgery. [18] So, there is no age limit for salvage urethroplasty. But, in the present study, age was limited up to thirteen years, as per admission criteria of paediatric units in the hospitals of Bangladesh, where paediatric units deals with patients up to thirteen years of age, at present. Hospital stay and Operation times are indirect measures of economic burden of the treatment. In present study buccal mucosal graft urethroplasty was associated with a significantly longer operation time and hospital stay than other groups under study. This was reflection of the fact that buccal mucosal graft urethroplasty was done in two stages and the calculated time was the summation of two stages. In the first stage, a full-thickness graft of buccal mucosa was used for urethral plate reconstruction. Second stage was carried out at least six months after the first procedure. However, as described by Dubey et al., [12] operation time could be reduced by two team approach. On the other hand, longer operation times and hospital stay in two stages did not negatively affect patient's compliance or outcome. In the present study early complications of urethrocutaneous fistula repair including bleeding, hematoma, wound infection, urinary retention was not troublesome and differences in three groups under study were insignificant. These findings were not consistent with Kessler et al. [19]; who reported a higher incidence of shortterm complications following skin flap procedures compared to free grafts. However intra-group analysis revealed that percentage of fistula recurrence among the three groups with previous secondary surgery were higher than corresponding primary surgery. This finding was in favour of the conventional thinking that each procedure would induce additional poorly vascularized scar tissue around the fistula and diminish the chances for subsequent successful repair. [20] In the present study transurethral stents were always used because an indwelling stent, inserted for few days, can 
support the healing urethra and prevent recurrences as suggested by Yassin et al. [21] However, some insignificant adverse conditions like stent block, kink, and inadvertent removal were observed in all three groups. Stent blockage was due to minor bleeding and inadequate hydration. Irrigation of stent with sterile normal saline, solved the problem. However, Urinary diversion via urethral or suprapubic catheters after fistula repair remained controversial. [22, 23] Catheter drainage was not recommended by Redman, [24] particularly in small fistulae. Eardley and Whitaker [25] routinely used catheter diversion, either urethral or suprapubic, for 7-14 days. Latifoglu et al. [26] concluded that a urethral catheter should be left for at least 5-11 days after repair. For assessment cosmesis and outcome a five-point scoring system had been devised by Holland et al., [27] termed the 'hypospadias objective scoring evaluation. This HOSE system was followed in present study. In present study an objective analysis of repair techniques with a valid comparison was made by using HOSE system. Among the three techniques the highest score gain was recorded in BM graft (182) and lowest score gain was for Flip flap methods (89). Duncan multiple range test (DMRT) demonstrated that the values of score gains were significantly different. But Very few studies have provided comparative data for different repairs performed in a uniform setting. Again, a recent survey of North American pediatric urologists clearly showed that there is a discrepancy between complication rates reported in the literature and the participants' operative outcomes, regardless of practice setting. [8]

In the present study, clinically obvious symptoms like a poor urinary stream, dribbling, spraying, or hesitancy were picked up and compared. Percentages of patients with obstructive voiding symptoms were higher in skin flap groups. When the patients with obstructive voiding symptoms were compared by significant post voidal residue by ultrasonography Buccal mucosal graft group was in a favourable situation but the differences were statistically insignificant. But, Assessment of functional outcome in nontoilet trained boys was. However, as commented by Springer [8], uroflow studies in small children is very time consuming and can be somewhat frustrating. On the other hand, ultrasound with measurement of post micturiton volume offered another non-invasive technique for postoperative assessment. Patient's satisfaction was very subjective, wide ranging and mainly depended on the ability of the patient to cope with cosmetic and functional abnormalities. Despite multiple previous failed surgeries, both parents and patients who have experienced failed hypospadias repair often easily accepted the idea of a staged approach that allowed a safer and more reliable final reconstruction. According to the results patient's compliance in present study, the best outcome was achieved with buccal mucosa whereas the worst outcome was with the use of skin in flip-flap. Similar conclusions were reached by Barbagli et al. [5] In present study, reoperative surgery was restricted to the urethral complications only to avoid complexity and to make the comparison critical, nonbiased and objective. However, even when a full circumferential substitution urethroplasty would require including repair of different compartments, a twostage buccal mucosal graft procedure would be the better option, because this had the advantage that, the varied anatomical issues could be fixed sequentially.

\section{Limitations of the Study}

Present study had several weaknesses, including the difficulty to collecting data on all patients covering all aspects of hypospadias history and subsequent repair. Yet again, we still know relatively little about the long-term behaviour and growth of less androgen-sensitive tissues, such as Buccal mucosa. Another limitation was that present analysis excluded post-pubertal patients. However, few men present for hypospadias repair during or after puberty. Excluding such patients allowed for easier comparison and decreased skewing of patient age distribution. Indefinite follow-up was beyond the scope of present study.

\section{Conclusion and Recommendations}

It is concluded that staged repair using buccal mucosa was a better option for urethral reconstruction in large $(>4 \mathrm{~mm})$ or multiple -small $(<4 \mathrm{~mm})$ fistulae, than dorsal transposition flap and flip flap procedures (group A $>$ group B > group C). In salvage procedures performed on failed hypospadias due to large and multiple fistulae, a staged repair with buccal mucosa, is recommended for a better outcome. Complication rates in reoperations are far greater than in primary repairs, implying that the quality of residual tissues is abnormal and the complexity of these repairs should not be underestimated. This is a challenging surgery and should not therefore be undertaken by surgeons who only dabble in this field.

\section{Source of Funding}

Self.

\section{Conflict of Interest}

None declared.

\section{Approval}

From respective department.

\section{References}

[1] Barbagli, G., Perovic, S., Djinovic, R., Sansalone, S., Lazzeri, M. (2010) Retrospective descriptive analysis of 1,176 patients with failed hypospadias repair. Journal of Urology. 183 (1), pp. 207-211.

[2] Bhat, A., and Mandal, AK. (2008) Acute postoperative complications of hypospadias repair. Indian Journal of Urology. 24 (2), pp. 241-248. 
[3] Shehata, SM., Elian, AA., Soliman SM., Hassan, HS. (2007) Re-Operative Repair of Mid Penile Hypospadias: Experience in 34 Cases. Annals of Pediatric Surgery. 3 (3), pp. 155-162.

[4] Secrest, CL., Jordan, GH., Winslow, BH., Horton, CE., McCraw, J., Gilbert, DA., Devine, CJ Jr. (1993) Repair of the complications of hypospadias surger. The Journal of Urology. 150 (5), pp. 1415-1418.

[5] Barbagli, G., Angelis, MD., Palminteri, E., Lazzeri, M. (2006) Reconstructive Urology -Failed Hypospadias Repair Presenting in Adults. European urology [online]. 49 (5), pp. 887-895. Available from: DOI: 10.1016/j.eururo.2006.01.027 [12 may 2014].

[6] Barbagl, i G., Palminteri, E., Guazzoni, G., Montors, i F., Turini, D., Lazzeri, M. (2005) Bulbar urethroplasty using buccal mucosa grafts placed on the ventral, dorsal or lateral surface of the urethra: are results affected by the surgical technique? Journal of Urology [online]. 174 (3), pp. 955-958. Available from DOI: 10.1097/01.ju.0000169422.46721.d7 [20 October 2014].

[7] Zhang, X., Li, LC., Zhou, SW., Zhou, XC., Yang, WM. (1995) Experience with Repair of Hypospadias Using Bladder Mucosa in Adolescents and Adults. The Journal of Urology [online]. 153 (4), pp. 1117-1119. Available from. https://doi.org/10.1016/S0022-5347(01)67526-8 [Accessed 1st March 2016].

[8] Springer, A. (2014) Assessment of Outcome in Hypospadias Surgery - A Review. Frontiers in Pediatrics [online]. 2 (2), pp. 2-19. Available from DOI: 10.3389/fped.2014.00002. [20 May 2016].

[9] Shahid, SMA., Nowshad, MA., Mostaque, A., Islam, SS. (2010) Outcome of urethral reconstruction in destile penile hypospadias by Tubularized Incised Plate urethroplasty: as a versatile technique. The Journal of Teachers Association, RMC, Rajshahi. 23 (1), pp. 26-32.

[10] Shahid, SMA., Mostafiz, R. (2011) Tubularized Incised Plate hypospadias repair: a multicenter experience. KhazaYunus Ali Medical College Journal. 1 (2), pp. 65-67.

[11] Yassin, T., Bahaaeldin, KH., Husein, A., Minawi, HE. (2011) Assessment and management of urethrocutaneous fistula developing after hypospadias repair. Annals of Pediatric Surgery [online]. 7 (2), pp.88-93. Availaible from DOI: 10.1097/01.XPS.0000397066.98404.82 [24 April 2017].

[12] Dubey, D., Vijjan, V., Kapoor, R., Srivastava, A., Mandhani, A., Anant Kumar, A., Ansari, MS. (2007) Dorsal Onlay Buccal Mucosa Versus Penile Skin Flap Urethroplasty for Anterior Urethral Strictures: Results From a Randomized Prospective Trial. The Journal of Urology. 178, pp. 2466-2469, Available from DOI: 10.1016/j.juro.2007.08.010 [28 November 2011].

[13] Retik AB., Keating, M., Mandell J. (1988) Complications of Hypospadias repair. The Urologic Clinics of North America. 15 (2), pp. 223-36.

[14] American Academy of Pediatrics, (1996) Timing of Elective Surgery on the Genitalia of Male Children with Particular reference to the risks, benefits, and psychological effects of Surgery and Anesthesia. Pediatrics [online]. 97 (4), pp. 590595. Available from: http://pediatrics.aappublications.org/content/97/4/590 [Accessed 20 May 2017].
[15] Castagnetti, M., El-Ghoneimi, A. (2010) Surgical management of primary severe hypospadias in children: systematic 20-year review. Journal Urology [online]. 184 (4), pp. 1469-1474. Available from DOI: 10.1038/nrurol.2013.164 [20 March 2015].

[16] Jones, BC., O’Brien, M., Chase, J., Southwell, BR., Hutson, JM. (2009) Early Hypospadias Surgery May Lead to a Better Long-Term Psychosexual Outcome. The Journal of Urology [online].182, pp. 1744-1750. Available from DOI: 10.1016/j.juro.2009.02.089 [20 December 2015].

[17] Weber, DM., Schonbucher, VB., Gobet, R., Gerber, A., Landolt, MA. (2009) Is there an ideal age for hypospadias repair? A pilot study. Journal of Pediatric Urology [online]. 5, pp. 345-350. Available from: DOI: 10.1016 /j.jpurol. 2008.12.008 [11 May 2014].

[18] Barbagli, G., Sansalone, S., Djinovic, R., Lazzeri, M. (2012) Surgical Repair of Late Complications in Patients Having Undergone Primary Hypospadias Repair during Childhood: A New Perspective. Advances in Urology [online]. Volume no [n.k.], (Article ID 705212), p. 5. Available from DOI: 10.1155/2012/705212 [24 March 2017].

[19] Kessler, TM., Schreiter, FM., Kralidis, G., Heitz, M., Olianas, R., Fisch, M. (2003) Long-term results of surgery for urethral stricture: a statistical analysis. The Journal of Urology. 170 (3), p. $840-844$.

[20] Elsaket, H., Habib, EM. (2009) Systematic Approach for the Management of Urethrocutaneous Fistulae after Hypospadias Repair. Egyptian journal of Plastic. Reconstrive Surgery. 33 (2), pp. 285-290.

[21] Karabulut, A., Sunay, M., Erdem, K., Emir, L., Erol, D. (2008) Retrospective analysis of the results obtained by using Mathieu and TIP urethroplasty techniques in recurrent hypospadias repairs. Journal of Pediatric Urology [online]. 4 (5), pp. 359-363. Available from: https://doi.org/10.1016/j.jpurol.2008.02.007 [21 December 2015].

[22] VanderWerff, JFA. (1999) Operative Strategies in Hypospadias - to divert or not to divert. In: The assessment of hypospadias. Rotterdam: Erasmus University Press, pp. 55-62.

[23] Shapiro, SR. (1999) Fistula Repair. In: Ehrlich, RM., Alter, GJ. (eds.) Reconstructive and Plastic Surgery of the External Genitalia; Adult and Pediatric. Philadelphia: WB Saunders Company, pp. 132-136.

[24] Redman, JF. (1993) Results of undiverted simple closure of 51 urethrocutaneous fistulas in boys. Urology [online]. 41 (4), pp. 369-371. Available from: https://doi.org/10.1016/00904295(93)90599-6 [Accessed19 May 2014].

[25] Eardley, I., Whitaker, RH. (1992) Surgery for Hypospadias Fistula. British Journal of Urology International [online]. 69 (3), pp. 306-310. Available from DOI: 10.1111/j.1464410X.1992.tb15534.x [12 April 2014].

[26] Latifoglu, O., Yavuzer, R., Unal, S., Cavuşoğlu, T., Atabay, K. (2000) Surgical treatment of urethral fistulas following hypospadias repair. Annals of Plastic Surgery. 44 (4), pp. 381386.

[27] Holland, AJA., Smith, GHH., Ross, FI., Cass, DT. (2001). HOSE; an objective scoring system for evaluating the results of hypospadias surgery. British Journal of Urology international. 88 , pp. 255-258. 